\title{
Sharing the journey of facilitator and learner: Online pedagogy in practice
}

\author{
Shirley Reushle \\ Faculty of Education \\ University of Southern Queensland, AUSTRALIA \\ reushle@usq.edu.au \\ Maxine Mitchell \\ University of the Sunshine Coast, AUSTRALIA \\ Mitchell@usc.edu.au
}

\begin{abstract}
Two perspectives are used to reflect on the learning design of a postgraduate online course - that of the designer/facilitator and that of the learner. While the course focus is on online pedagogical approaches, the main aim is to connect learners with each other and with the facilitator so that together they may investigate, trial, challenge and formulate ideas about online pedagogy. The design is influenced by the principles of transformative learning where the concept of a "dilemma" leads to disorientation and then to learning. Learners are presented with a number of educational dilemmas, given a process for addressing those dilemmas and are required to authentically demonstrate how principles and practices can be applied to enhance online learning and teaching. The design addresses the theory/practice nexus and illustrates that research is best situated in real world contexts, and effective practice should be framed and informed by research.
\end{abstract}

Keywords

Online pedagogy, transformative learning, dilemmas, authentic assessment.

\section{Introduction - starting the journey}

In this paper, the authors critique the learning design of a postgraduate online course, Online Pedagogy in Practice from the perspectives of Author 1 (the course designer/facilitator) and Author 2 (the learner) to demonstrate alignment between design and authentic learning experiences that promote rich environments of theory-embedded practice. The course is offered in the Faculty of Education Masters program at the University of Southern Queensland. Author 1 drew on her doctoral research into transformative learning (Reushle, 2005) and her experience as an online educator to design and facilitate the course. She provides this background:

My interest in transformative learning emerged from a serendipitous incident which occurred in the early stages of my doctoral study in 2000. On a whim, I attended a Transformative Learning conference in the USA and found myself surrounded by positive, supportive, enthused educators - for me a transformative experience as my educational perspectives were both challenged and affirmed. This set me on a path to find out more about transformative learning and how the principles could be applied to my practice as an online educator. Despite the lack of extant research at that time linking the concept of transformation to learning online, I felt that online settings could provide a "friendly" environment that would support learning contexts promoted by adult education theorists such as Knowles (1990), Mezirow (1991) and Cranton (2003) - collaborative, interactive learning communities that support and promote transformative learning. 
Author 2 provides an account of her experiences in the course and how participating in the course challenged her conception of online pedagogy. She provides this background:

My goal for studying the Master of Online Education was to advance my career prospects, capitalising on my strengths to influence my career direction. The Masters program was the vehicle to orientate myself into this new world - the online learning phenomena. In particular, the course which is the focus of this paper enabled me to test my assumptions, practices and beliefs against external reference points - the educational literature, my peers, the facilitator and the course content, and validate these experiences in my work context. My experience in the course enabled me to align my teaching philosophy and practice with the educational literature. It facilitated the marrying of theory and practice, but better, built my confidence to advance my teaching that resulted in a seamless exchange between theory and the practical applicability to my professional life. My studies have given me the confidence to explore, negotiate, challenge, interact and collaborate across boundaries to enhance my professional knowledge and practice. As an advocate of lifelong learning, the Master of Online Education has positioned me as an active inquirer in my own learning.

\section{Learning design - theoretical framework}

While the course is focused on pedagogical approaches to online learning, the main aim is to connect the learners so that together they may explore, investigate, formulate and challenge their own ideas - and the ideas of others - about online pedagogy. The course design draws on existing theory and knowledge relating to the following themes evident in the literature:

- theories of learning, particularly transformation theory (transformative learning),

- learning and teaching in online settings (online pedagogy), and

- $\quad$ principles of adult learning.

The design reflects the concept of learning as a lifelong journey where adults have a wealth of experience on which to draw. The design focus is on providing authentic activity that is taskcentred, practical and with immediate application to the learner's work and takes into account the self-directedness of adults who can usually identify their learning needs and most often pace themselves. Adults prefer flexibility, but with structure and purpose - educational experiences that are isolated and unrelated to the "now" can be irrelevant for these learners. Adults also need to be able to reflect - on the activity, on the content, on their interactions with others and then relate it to what they already know and do (Knowles, 1990).

The course design is shaped by transformative learning principles and the concept of a dilemma leading to disorientation and then to learning (Mezirow, 1991). According to Mezirow (1991), all meaning is based on the learner interpreting experience with the critical dimension of an adult's learning being reflection, or the process of validating ideas and assumptions based on prior learning. He believes the role of the educator is to help learners focus on, and examine, the assumptions that underlie their beliefs, feelings and actions, assess the consequences of these assumptions, identify and explore alternative sets of assumptions, and test the validity of assumptions through effective participation in reflective dialogue. Transformative learning is the process by which we call into question our taken for granted habits of mind or mindsets to make them more inclusive, discriminating, open and reflective in order to guide our actions. Mezirow (1991) states that transformative educators should facilitate dialogue to help others, and perhaps themselves, explore beliefs and to move towards a fuller and more dependable understanding of the meaning of experiences. According to the tenets of transformative learning, adult learners need to be reflective, critical thinkers who are open to other perspectives and accepting of new ideas. Dialogue is crucial in this process. A transformative educator should aim to engender a sense of community and provide a safe place for exploration and discovery through shared trust and a sense of possibility (Cranton \& Wright, 2007). 


\section{..."dilemmas"...leading to learning...}

Catalysts for transformative learning, according to Mezirow (1991) are "disorienting dilemmas", situations that do not fit one's preconceived notions. These dilemmas prompt critical reflection and in the event of a new experience, our existing meaning perspectives (our central meaning structures) "act as a sieve through which each new experience is interpreted and given meaning" (Taylor, 1998, p. 7). The interpretation of this new experience may either reinforce existing perspectives, be rejected, or an existing meaning perspective may be transformed to accommodate the new experience.

This concept is reflected in the course design where learners are presented with a number of educational dilemmas or triggers - for example, "how to create and sustain a sense of presence in an online learning environment" - and are provided with a process to engage rigorously with the dilemma content, with each other and the facilitator to explore appropriate theory and related practice. The course assessment requires the learners to practically demonstrate how principles and practices can be applied to enhance online learning and teaching by conducting a pedagogical event in the virtual environment using their peers as learners. In addition, guided by a number of stimulus questions, learners keep a reflective diary of their learning journey accompanied by their analyses of changes in their perspectives and the resultant pedagogical shifts in their approaches to learning and teaching.

The concept of a dilemma leading to disorientation (Mezirow, 1991) and then to learning is not a new one. In Dewey's (1933) work, he declared that the capacity to reflect is initiated only after recognition of a problem or dilemma and the acceptance of uncertainty. Learning is driven by the learner's sense of disequilibrium (cognitive dissonance) when confronted by new experiences and ideas, rather than by reinforcement of existing ideas. The dissonance created in understanding that a problem exists engages the reflective thinker to become an active inquirer, involved both in the critique of current conclusions and the generation of new hypotheses. Dewey believed that traditional reinforcement of information only led to superficial learning. He believed the educator to be responsible for creating events in which the learner is presented with problematic situations that he/she would be motivated to solve.

The theoretical concept of disorientation/dissonance/disequilibrium leading to learning is at the heart of the work of other developmental theorists such as Bruner (1960) and Piaget (1952) and these concepts are evident in much of more recent educational thinking. What Dewey (1933) referred to as "perplexity, hesitation, doubt", Greene (1975) calls "dislocations", Brookfield (1987) refers to as "inner discomforts" and Larrivee (2000) identifies as "inner conflict" or "inner turmoil". Greene (1975) believes that a learner's central concern is with "ordering [or bringing harmony to] his own life-world when dislocations occur" (p. 307) - when the learner experiences "moments when the recipes he has inherited for solving problems no longer seem to work", or when "what was once familiar abruptly appears strange" (Greene, 1997, p. 142). The failure of recipe learning often leads to critical reflection and perspective transformation (a world view shift), a move "beyond what she has been" (Greene, 1997, p. 139). She notes that "it is at moments like these that the individual reaches out to reconstitute meaning, to close the gaps, to make sense once again". Reference to "critical incidents" parallels the concept of disorienting dilemmas.

However, the disorientation caused by dilemmas must be carefully monitored to ensure that their impact does not result in negative outcomes for the learner. It is one thing to be disoriented but to have a compass or map on hand; it is another situation entirely to be totally lost without any support or guidance!

The course design aims to dispel the myth of the theory-practice divide. Rather than theory and practice being separate and even mutually exclusive, the intent is to demonstrate the interconnectedness of the two. That is, effective educational research must be situated in real world contexts and effective practice must be explicitly framed and informed by research. 


\section{Author 2 (the learner) observes that:}

...the learning design intentionally establishes a series of learning experiences that require the learners to situate themselves on the structure-flexibility continuum and take responsibility for shifts along this continuum as the learning episodes unfold.

\section{The facilitator's perspective: assessment as authentic experience}

Boud (2000) advocates that assessment practices should prepare learners to be effective in the learning society and equip individuals with a learning approach for life, that is, assessment should enhance learning and be an integral part of the learning and teaching process. The role of assessment is also to enable learners to make judgements about their learning by engaging in selfassessment rather than considering each task as a discrete event in their learning journey. A key aim of the course design is to create opportunities for learners to explore online pedagogy in practice - a "prac online" experience.

As previously mentioned, the course design presents learners with a number of educational dilemmas or triggers (called "themes") and provide a process for addressing those dilemmas. Learners are encouraged to engage rigorously with online learning and teaching theories and work collaboratively to consider, explore, trial and adapt online pedagogical principles in practice. Each theme is accompanied by suggestions for focus topics and a selection of online literature.

Themes include:

- Creating and sustaining a sense of presence online;

- Creating and sustaining online learning communities;

- Promoting and supporting online conversations;

- $\quad$ Finding tools to support online pedagogy;

- Providing authentic assessment and meaningful feedback in online environments;

- Nominating your own dilemma.

Learners maintain a diary or journal of events and dilemmas or critical incidents throughout the semester along with associated reflective thoughts. The purpose of reflective tasks is to assist the learner in making meaning from their personal experiences. Given that the underlying educational purpose of the course is to focus on online pedagogical approaches that connect learners with each other and with the facilitator to enact a learning community approach, learners are encouraged to consider any number of ways to maintain this diary, mediated through web applications including blogging, wikis and discussion forums to provide a shared account of their journey through the learning dilemma.

Course assessment consists of a five-stage process that aligns with Mezirow's (1991) phased approach to addressing disorienting dilemmas. Learners select a dilemma, focus on their own context, but work as a community of learners. Because the success of the course relies very much on learning as a community process and on understanding roles and responsibilities within a group, learners are guided through a group formation process early in the course.

Table 1 illustrates how the stages of assessment relate to the phases of addressing a dilemma. The topic ("providing authentic assessment and meaningful feedback in online environments") selected by Author 2 (the learner) of this paper has been used as an example. 
Table 1: Assessment stages and dilemma phases

\begin{tabular}{|c|c|c|c|}
\hline $\begin{array}{l}\text { Assessment } \\
\text { stages }\end{array}$ & $\begin{array}{l}\text { Dilemma phases } \\
\text { (Mezirow, 1991) }\end{array}$ & Questions, activities & Marks \\
\hline $\begin{array}{l}1 \text { Guided } \\
\text { preparation of a } \\
\text { literature review }\end{array}$ & $\begin{array}{l}1 \text { Experience } \\
\text { disorienting dilemma } \\
\text { and undergo self- } \\
\text { examination } \\
2 \text { Presentation of a } \\
\text { dilemma }\end{array}$ & $\begin{array}{l}1 \text { What issue concerns you? What do you } \\
\text { want to find out more about? } \\
2 \text { What does the literature say about } \\
\text { authentic assessment and the provision of } \\
\text { meaningful feedback? } \\
3 \text { Define authentic assessment, meaningful } \\
\text { feedback }\end{array}$ & 20 \\
\hline $\begin{array}{l}2 \text { Participation in } \\
\text { and contribution } \\
\text { to discussion } \\
\text { activities }\end{array}$ & $\begin{array}{l}2 \text { Critical assessment } \\
\text { of the dilemma } \\
3 \text { Exploration and } \\
\text { consideration of } \\
\text { options and courses of } \\
\text { action }\end{array}$ & $\begin{array}{l}1 \text { How can I ensure that assessment in my } \\
\text { online environments is authentic? } \\
2 \text { How can I ensure feedback is } \\
\text { meaningful, timely and effective? }\end{array}$ & 10 \\
\hline $\begin{array}{l}3 \text { Facilitate and } \\
\text { conduct a } \\
\text { pedagogical } \\
\text { (teaching) event } \\
\text { online }\end{array}$ & $\begin{array}{l}4 \text { Planning a course of } \\
\text { action } \\
5 \text { Acquiring knowledge } \\
\text { and skills for } \\
\text { implementing one's } \\
\text { plans } \\
6 \text { Provisionally trying } \\
\text { out new roles } \\
7 \text { Building of } \\
\text { competence and self- } \\
\text { confidence in a safe } \\
\text { environment }\end{array}$ & $\begin{array}{l}1 \text { Select means of creating authentic } \\
\text { assessment and meaningful feedback } \\
2 \text { Facilitate a teaching event online that } \\
\text { demonstrates authentic } \\
\text { assessment/meaningful feedback } \\
3 \text { Ensure the activity is relevant to you and } \\
\text { your professional practice. Ensure there is } \\
\text { a sense of substantive, meaningful } \\
\text { purpose for the existence of this activity. } \\
4 \text { Each group member to participate in a } \\
\text { seminar discussion around this topic }\end{array}$ & 20 \\
\hline \multirow[t]{2}{*}{$\begin{array}{l}4 \text { Prepare and } \\
\text { present a paper } \\
\text { at the Virtual } \\
\text { Seminar }\end{array}$} & $\begin{array}{l}8 \text { A reintegration into } \\
\text { society on the basis of } \\
\text { conditions dictated by } \\
\text { the new perspective }\end{array}$ & $\begin{array}{l}1 \text { Prepare a joint or individual paper } \\
\text { according to the author guidelines provided } \\
\text { (suitable for publication) }\end{array}$ & 30 \\
\hline & & $\begin{array}{l}2 \text { Present the paper at the Virtual Seminar } \\
\text { and invite interaction with peers }\end{array}$ & \\
\hline 5 Reflective diary & & Maintained throughout the course & 20 \\
\hline
\end{tabular}

Author 1 (the designer/facilitator) makes this observation about her own reflective practice:

Keeping my own reflective journal and taking the opportunity to write about the course with one of my students has enabled me to better understand professional practice by interrogating and challenging my assumptions and practice and seeking inspiration and guidance to alter my perspectives and improve that practice. In addition to keeping a journal, I invite learners, partway through the course to give anonymous feedback on the course and on their experiences and I use this feedback to help guide my in action decisionmaking. To reflect in action (while doing something) and on action (after you have done it) should be integral to the role of a reflective practitioner.

\section{The learner's perspective: learning design and authentic learning experiences}

As an adult learner reflecting on her experiences in the course Online Pedagogy in Practice, I was fascinated by the way the course opened the flood gates in my confidence to explore, negotiate, challenge, interact and collaborate across pedagogical and physical boundaries. 
My positive learning experiences are in direct contrast to the findings of Garrett (2004) who cites many online projects that failed to realise their aims and goals which has led to questions about the quality and capabilities of online as a form of educational delivery. This "dissonance" between my reality and that described by Garrett (2004) prompted me to counter the misrepresentation of online pedagogy by critiquing the alignment between learning design and authentic learning experiences in this course.

The staged assessment task required the learners to self-nominate into groups based on shared interest. I joined a group which we named the Online Pedagogy Networkers and chose to focus on the topic of authentic assessment. A key design element of the course is for the assessment tasks to align with real-world tasks of professional practice. This meant the assessment tasks created an individualised, personalised learning experience that authenticated the application of theoretical knowledge to the learner's professional real-life. Further, the problems inherent in the assessment tasks were intentionally ill-defined and open to multiple interpretations rather than easily solved by the application of an existing sequence of instructions. Learners were required to identify their own unique tasks and sub-tasks, and challenge their own beliefs and attitudes in order to make sense of and complete the staged activities in the assessment task (Mezirow, 1998; Herrington, Oliver \& Reeves, 2003). The pedagogical tools of authentic assessment and learning dilemmas enabled me to construct and critically reflect on my knowledge by situating it in my own profession practice. I was able to evaluate my learning through collaboration and interaction with my peers in an online community of practice.

A cautionary note is required though. Assessment tasks that guide in the exploration of learning dilemmas require a level of sophistication in the teacher's philosophy of learning and teaching. The course facilitator had a clear assessment vision and was able to articulate that vision to students by establishing an unambiguous purpose and theoretical framework around the learning dilemma that served as signposts for students to connect theory to practice as they challenged their meaning scheme. While learners had flexibility to self-select approaches, processes and even the end product to be successful in the assessment tasks, there was a structured framework that intentionally acted as points of reference as learners faced their inner discomforts and disorientations from actively engaging in the dilemma activity and with each other. As I experienced this inner turmoil and conflict, the structure served as 'just-in-time' learning - it was there as a learning resource to sustain my transition from disorientation to transformation, enabling the alignment of learning tasks, learning resources and learning support (Oliver, 2005). In addition, the facilitator cultivated a nurturing, supportive learning environment where students felt empowered to interpret and experiment with their peers, construct new knowledge and be in charge of the learning process.

There are a number of other design elements that support the principles of transformative learning in an online environment. The text-based nature of dialogue enabled learner-learner, learnerfacilitator and learner-content interaction to be visible and accessible to all students. The layers of interaction stimulated peer conversations, collaboration and a collegial atmosphere that allowed me, as a learner, to operate socially and affectively in a virtual learning space. The online environment also provided opportunities for me to access, share, digest and critique information quickly and easily. 
The facilitator utilised a number of tactics to create a supportive, safe learning environment such as: establishing a clear purpose, structure and expectations; providing collaborative, shared spaces such as discussion forums for introductions and student profiles; using 'ice-breaker' activities to encourage a supportive atmosphere and human presence; using emoticons and informal written text to promote online 'friendliness' (talk to you soon; see you tomorrow); and modelling a read, reflect and respond approach to encourage questions and online dialogue. This provided documentary evidence of the student's learning and integration of new ideas with existing knowledge as they interpreted and addressed their learning dilemmas. This also provided a platform for critical reflection and self-evaluation to give meaning to the learning experience. When I reflect on this experience, I cannot put a metric on the knowledge generation, growth and emotional reactions I have experienced. The course demystified online pedagogy and built my confidence to position myself as an online practitioner demonstrating a focus on the learning process rather than the learning product. Author 1 experienced delight in reading the learner's final reflective statement where she remarks:

As this is the final course in my Master of Online Education, the reality of how it has reconfirmed my passions and direction, while cross-pollinating a number of future opportunities for me, is an incredible and exciting outcome. This course... has helped to transition me into the next stage of my lifelong learning journey.

Herrington et al. (2003) advocates a number of design elements to ensure that authentic assessment tasks achieve authentic learning in an online learning environment. Table 2 compares these design elements with the assessment tasks in the course.

Table 2: Design elements for authentic tasks in Online Pedagogy in Practice

Design elements
(Herrington et al., 2003) How assessment tasks achieve authentic learning in the course

Authentic tasks have real- The assessment tasks align to the real-world tasks of professional world relevance practice. This meant the assessment tasks create an individualised, personalised learning experience that authenticates the application of theoretical knowledge to the learner's professional real-world.

Authentic tasks are illdefined, requiring students to define the tasks needed to complete the activity

Authentic tasks are seamlessly integrated with assessment
The problems inherent in the assessment tasks are intentionally illdefined and open to multiple interpretations rather than easily solved by the application of an existing sequence of instructions. Learners are required to identify their own unique tasks and sub-tasks, and challenge their own beliefs and attitudes in order to make sense of and complete the activities.

Assessment stages 2, 3 and 4 are intentionally scaffolded into the next stage of learning to enable students to make judgements and descriptions of their work and the work of their peers. The reflective diary (stage 5) requires students to critically reflect on their journey, evaluate their achievements and actions, and situate their reflection in their professional real-world. Stage 5 also asks students to speculate on the next stage of their lifelong learning journey.

Authentic tasks comprise complex tasks to be investigated by students over a sustained period of time

The assessment stages adopts a learning-centred approach which focuses on the learning to be achieved over a sustained period in the course. It requires significant investment of time, intellect and resources at the individual and collaborative group level to digest, interpret, construct an understanding, and identify a pathway to achieve success in the assessment task.

Authentic tasks provide the opportunity for students to examine the task from different perspectives using a variety of resources
All assessment tasks adopt a learner-centred approach that provide students with the opportunity to examine the task from a variety of theoretical and practical perspectives, rather than from a single perspective that learners must imitate to be successful. Further, students are encouraged to situate their life experiences and professional practice in the process of learning to achieve the 
requirements of the assessment tasks. Students are provided with a range of resources as a starting point in the learning dilemma and encouraged to investigate and explore the context surrounding the dilemma to stimulate autonomous, self-directed thinking.

\begin{tabular}{ll}
\hline $\begin{array}{l}\text { Authentic tasks provide } \\
\text { the opportunity to }\end{array}$ & $\begin{array}{l}\text { The social and collaborative nature of the staged assessment, and } \\
\text { the design and facilitation of the course in general, foster a } \\
\text { collaborate }\end{array}$ \\
$\begin{array}{l}\text { community of learners that enable students to share experiences and } \\
\text { professional practice, learn from each other and assimilate the new } \\
\text { learning experiences into the individual's knowledge structures. The } \\
\text { assessment tasks result in a rich diversity of ways in which students } \\
\text { engage with the learning dilemmas. }\end{array}$
\end{tabular}

Authentic tasks provide the opportunity to reflect
All assessment tasks enable the learners to make choices and interpret the meaning of the assessment task framework. This fosters critical reflection and self-assessment to challenge the learner's meaning scheme resulting in students achieving a deeper approach to learning.
The assessment tasks and learning activities embrace and encourage interdisciplinary perspectives which enable diversity in roles, expertise and practice to be integrated into the construction of knowledge and understanding at the individual and collaborative level. Further the assessment tasks and related activities encourage diversity of outcomes, and are open to multiple solutions stemming from the original context.

Table 2 provides evidence that the assessment tasks in this course are designed to have real-world relevance and utility. Further, the assessment tasks provide appropriate levels of complexity that enable students to select the level of difficulty or involvement that challenges their meaning scheme resulting in a holistic rather than fragmented learning experience. This encourages learners to be self-assessors of their learning (Jonassen, 1991, as cited in Herrington et al., 2003; Boud \& Falchikov, 2007). When online pedagogy embraces a holistic approach to authentic assessment and learning dilemmas, students develop the skills, knowledge and capacity to transfer their learning to a range of situations in their professional world.

\section{Conclusion}

This paper has been written to share the intent of the designer/facilitator of a postgraduate online course and the experiences of a learner in that course. In contemporary societies, where the challenge for educators is to prepare learners to engage effectively with situations in their professional lives, quality learning experiences must cultivate authentic activity that develops transferable skill sets, fosters critical reflection, challenges learner perspectives and engenders new ways of seeing and doing. The course design aims to dispel the myth of the theory-practice divide. Rather than theory and practice being separate and even mutually exclusive, the intent is to demonstrate the interconnectedness of the two. That is, effective research must be situated in real world contexts and effective practice must be explicitly framed and informed by research.

The design described in this paper reflects Mezirow's (1991) view of transformative learning and demonstrates that one of the roles of the educator is to guide the learner to focus on and examine the assumptions that underlie their beliefs, feelings and actions, assess the consequences of these assumptions, identify and explore alternative sets of assumptions and test their validity through effective participation in reflective dialogue. The paper advocates online pedagogy as a means of providing rich diversity in learning experiences by demonstrating the connectedness between learning design, the principles of transformative learning and the ability of the learning experiences to reflect effective practice in real life. This aims to demonstrate the notion of authentic assessment. 
The learning design evokes the principles of adult learning and promotes a learner-centred approach. This challenges the learner to interpret new experiences through a journey of supported educational dilemmas and experience disorientation and critical reflection in order to reconstitute meaning and understanding within a guided learning community.

\section{References}

Boud, D. (2000). Sustainable assessment: rethinking assessment for the learning society. Studies in Continuing Education, 22(2), 151-167

Boud, D., \& Falchikov, N. (Eds.) (2007). Rethinking assessment for higher education: Learning for the longer term. London: Routledge.

Brookfield, S. (1987). Developing critical thinkers: Challenging adults to explore alternative ways of thinking and acting. San Francisco: Jossey-Bass.

Bruner, J. (1960). The process of education. Cambridge, MA: Harvard University Press.

Cranton, P. (2003). Finding our way: A guide for adult educators. Toronto: Wall \& Emerson, Inc.

Cranton, P., \& Wright, B. (2007). The transformative educator as learning companion. In Transformative learning: Issues of difference and diversity. Eds P. Cranton \& E. Taylor, Albuquerque, New Mexico: University of New Mexico College of Education.

Dewey, J. (1933). How we think: A restatement of the relation of reflective thinking to the educative process. Lexington, MA: Heath.

Garrett, R. (2004). The real story behind the failure of the UK eUniversity. Educause Quarterly, 4, 3-6. Retrieved August 1, 2008, from http://net.educause.edu/ir/library/pdf/eqm0440.pdf

Greene, M. (1975). Curriculum and consciousness. In W. Pinar (Ed.), Curriculum theorizing: The reconceptualists (pp. 299-317). Berkeley: McCutchan.

Greene, M. (1997). Curriculum and consciousness. In D. J. Flinders \& S. J. Thornton (Eds.), The curriculum studies reader (pp. 137-149). New York, London: Routledge.

Herrington, J., Oliver, R., \& Reeves, T.C. (2003). Patterns of engagement in authentic online learning environments. Australian Journal of Educational Technology, 19(1), 59-71. Retrieved August 28, 2008, from http://www.ascilite.org.au/ajet/ajet19/herrington.html

Knowles, M. S. (1990). The adult learner: A neglected species (4th ed.). Houston: Gulf Publishing Company.

Larrivee, B. (2000). Transforming teaching practice: Becoming the critically reflective teacher. Reflective Practice, 1(3), 293-207.

Mezirow, J. (1991). Transformative dimensions in adult learning. San Francisco: Jossey-Bass.

Mezirow, J. (1998). Transformative learning and social action: A response to Inglis. Adult Education Quarterly, 49(1), 70-73

Oliver, R. (2005). Using blended learning approaches to enhance teaching and learning outcomes in higher education. Proceedings of the International Association of University Presidents' Teaching Showcase. Joonadalup, WA: Edith Cowan University.

Piaget, J. (1952). The origins of intelligence in children (M. Cook, Trans.). New York: International Universities Press, Inc.

Reushle, S. E. (2005). Inquiry into a transformative approach to professional development for online educators, doctoral thesis, USQ.

Taylor, E. W. (1998). The theory and practice of transformative learning: A critical review. Information Series No. 374. Columbus, USA: ERIC Clearinghouse on Adult, Career, and 
Vocational Education, Center on Education and Training for Employment, College of Education, Ohio State University.

(c) Copyright Shirley Reushle and Maxine Mitchell [2009.

Please cite as: Reushle, S. \& Mitchell, M. (2009). Sharing the journey of facilitator and learner:

Online pedagogy in practice. Journal of Learning Design, 3(1), 11-20. http://www.jld.qut.edu.au. 